Portland State University

PDXScholar

$12-12-2021$

\title{
Collaborative Digital Problem-Solving: Power, Relationships, and Participation
}

\author{
Gloria E. Jacobs \\ Portland State University, gljacobs@pdx.edu \\ Jill Castek \\ University of Arizona
}

Follow this and additional works at: https://pdxscholar.library.pdx.edu/ling_fac

Part of the Applied Linguistics Commons

Let us know how access to this document benefits you.

\section{Citation Details}

Jacobs, Gloria E. and Castek, Jill, "Collaborative Digital Problem-Solving: Power, Relationships, and Participation" (2021). Applied Linguistics Faculty Publications and Presentations. 73.

https://pdxscholar.library.pdx.edu/ling_fac/73

This Post-Print is brought to you for free and open access. It has been accepted for inclusion in Applied Linguistics Faculty Publications and Presentations by an authorized administrator of PDXScholar. Please contact us if we can make this document more accessible: pdxscholar@pdx.edu. 


\title{
Collaborative Digital Problem Solving: Power, Relationships, and Participation
}

\author{
Abstract \\ The study examines the collaborative nature of problem solving as dyads and triads of adults \\ were grouped to solve digital problems using online resources. Digital problem solving involves \\ the nimble use of skills, strategies, and mindsets to navigate online in everyday contexts using \\ novel resources, tools, and interfaces, in efficient and flexible ways, to accomplish personal and \\ professional goals. Findings address the nature of collaborative talk during digital problem \\ solving through three interrelated categories of themes gleaned from discourse analysis: (a) \\ power, (b) relationships, and (c) participation. These themes offer a nuanced understanding of \\ collaborative interactions during digital problem solving. Implications from this research suggest \\ ways to design collaborative activities and support dialogic interaction, whether among \\ adolescents or adults, during online learning, in formal education settings or informally in other \\ settings where collaboration occurs. \\ Key words: Adolescent learning, Adult learning, Collaboration, Digital literacies, Problem \\ solving
}

\section{Introduction}

Online networks and search engines are often the first place people turn to when seeking information or attempting to solve a problem in everyday life. Although digital problem solving can and does happen individually, the digital world is a collaborative world (Jenkins, 2006) and people often turn to friends and family for help (Helsper \& van Deursen, 2017). Collaboration is one of the key elements of participatory culture made possible by the internet (Jenkins, 2006) and is also a way to learn digital skills. Collaborative problem solving can support the acquisition 
of digital literacies, and it can help individuals develop the skills necessary for engagement in the online world.

Jacobs et al. (2015) show collaboration is important for individuals with limited access and skills in using digital tools. Understanding that collaboration and consequent learning looks different depending on power, relationships, and participation dynamics can help education practitioners design and support digital learning opportunities.

The research described in this article was designed to learn about the digital problem solving of underserved adults. Castek et al. (2018a) define digital problem solving as the "nimble use of skills, strategies, and mindsets to navigate online in everyday contexts using novel resources, tools, and interfaces in efficient and flexible ways to accomplish personal and professional goals" (p. 2). The study is grounded in the literacies as a social practice tradition (Barton, 2001; Barton \& Hamilton, 1998; Barton, Hamilton, \& Ivanic, 2005; Gee, 2000; Heath, 1982; Street, 1984). The use of text is social, and the definition of literacy is evolving due to the prevalence of digital texts, tools, and applications that are ubiquitous within daily interactions (Leu et al., 2013).

An examination of the talk that occurs during collaboration provides insights into the nature of digital problem solving. The purpose of this article is to examine what collaborative digital problem solving looks like. Identifying patterns of collaborative digital problem solving can help practitioners construct opportunities to support learning and help researchers move toward new understandings of the nature of collaboration.

\section{Review of the Literature}

Research in digital literacies among adult learners tends to focus on individuals' learning experiences (Barrie et al., 2020) or learners working online collaboratively (Sharp, 2018). There 
is little research into the collaborative nature of digital problem solving among underserved adults that takes place in informal, self-directed learning environments.

Digital literacies refers to figuring things out rather than learning keystrokes or how to use software packages (van Laar et al., 2017). The American Library Association (2013) defines digital literacy as the ability to use information and communication technologies to find, evaluate, create, and communicate information. Jacobs and Castek (2018) adopt an expanded view of literacy and digital literacies that include social practices such as navigating individually and collaboratively online, using digital and online tools efficiently, and engaging in digital networking. With the internet being the first, primary, or sometimes only point of contact for healthcare, housing, education and educational resources, transportation, banking, and shopping, digital literacy practices are an integral part of everyday life (Sieck, Sheon, Ancker, et al., 2021). Problem solving includes a series of complex cognitive operations and involves higherorder thinking processes that support continuous learning (van Laar et al., 2017). Problem solvers use strategies to reach a solution. When it is clear that a solution cannot be reached, they must make a change. During digital problem solving, an individual engages in critical thinking when examining different websites and resources, determining which ones are the most useful, and for deciding which information within any given resource is relevant (Jacobs \& Castek 2018). In addition to thinking critically about information, learners also need to rapidly shift perspective and adapt their skills to complex situations they have not encountered before. Consistent with Kiili, Leu, Utrainen, Coiro, et al.'s (2018) framing of online reading as a discovery orientation, digital problem solving involves learning how to learn within everchanging digital environments.

\section{Collaboration and Digital Problem Solving}


Jenkins (2006) defines collaborative problem solving as the ability to work in formal and informal teams to complete tasks and develop new knowledge. Collaboration occurs online and can be learned while engaging in online practices. When technology itself is a barrier (Rosen \& Vanek, 2017), in-person collaboration may be needed to build skills. Van Laar et al. (2017; 2018) define collaboration as the ability to use digital technology to develop a social network, work in a team, exchange information, and make decisions in order to achieve a common goal.

Helsper and van Deursen (2017) suggest that collaboration with friends and family is a common solution for problem solving among adults but is often insufficient. Family members or friends may not always be available, may be reluctant to provide help, or may be impatient (Courtois \& Verdegem, 2016). Even when individuals are able to get help, the assistance they receive is not necessarily of high quality (Helsper \& van Deursen, 2017). However, these issues should not negate the power of informal social learning. Examining social dynamics may provide insight into what constitutes powerful collaborative digital problem solving.

Lin, Hou, and Tsai (2016) identified five core processes that occur as part of social knowledge construction: (a) sharing and comparing information, (b) discovering inconsistencies among participants, (c) negotiating meaning, (d) examining the proposed project, (e) and applying the constructed meanings. Lin et al. found that online information seeking behavior and collaborative discussion were closely related. They argue that being aware of inconsistencies in understandings between collaborators helped with the negotiation of meaning and built group cohesion. How collaborators coordinated tasks was intertwined with building knowledge.

\section{Methods}


The analysis discussed in this article addressed the collaborative nature of digital problem solving. Data are taken from a larger study reviewed and approved by the university's Institutional Review Board. The larger study (detailed in Jacobs \& Castek, 2018) involved approximately 450 library users. A public library system was selected as the research site because public libraries are the main gateway for internet services for many people in underserved communities. All participants were able to speak and read English. All 450 library users completed a library use survey, and 211 completed the Problem Solving in Technology Rich Environments (PSTRE) assessment (OECD, 2009). We observed and screen recorded an additional 15 participants while they engaged in digital problem solving using the PSTRE and additional library tasks designed by the research team. The team consisted of literacy education researchers, graduate students, adult education practitioners, and administrators and staff from the public library system.

Our 15 participants were recruited through the public library's outreach programs. Two were "Friends of the Library" recruited as experienced library website users, and 13 were houseless or lived in transitional or subsidized housing. The observational protocol focused on participants' digital navigation. All participants who were observed received a $\$ 40$ stipend.

\section{Participants}

This article focuses on seven participants. After reviewing the data from all 15 of the observed participants, we selected seven individuals (two dyads and one triad) as being illustrative of the patterns of digital problem solving identified through data analysis. Of the seven, three participants accessed the internet primarily from home, three were dependent on the library, and one primarily accessed it from her place of employment, although she did have home access. During the observation, participants were partnered with people they did not know, with 
the exception of Henry, Sam, and Andrew who knew each other from their transitional housing community and asked to be scheduled at the same time. Sonja and Francis were each partnered with a participant recruited from the "Friends of the Library". The intent was to partner a less experienced individual with a more experienced individual.

Of the seven, only Carla was employed at the time of the study. Ellen was retired, and the rest were unemployed. Three identified as women, three as men, and one as nonbinary. Six of the participants had some level of post-secondary education, although only three had attained degrees. Data were not collected on the number or type of courses taken at the post-secondary level or when they attended post-secondary classes. For the purposes of the analysis in this article, access and experience, along with life conditions such as unemployment and houselessness, are used to contextualize the lives of the participants as they collaborated and problem solved. It is beyond the scope of this article to consider any of these conditions as variables that influence problem solving skills. Table 1 contains participants' demographics.

************Insert Table 1 about here $* * * * * * * * * * * * * * * * * * * * * * * * * * *$

\section{Data sources}

A background survey was used to collect demographic information, internet and library use practices, and the participants' self-reported self-efficacy for digital problem solving. Information on housing was revealed incidentally by the participants during the interviews. The PSTRE was initially selected as the instrument for assessing digital problem skills based on the publication of the PSTRE framework (OECD, 2009). After implementing the PSTRE with 211 participants in the larger study, the research team realized that digital problem solving differs from problem solving in technology rich environments. The PSTRE measures cognitive skills assessed in a controlled setting, whereas digital problem solving occurs within everyday settings 
based on life purposes and goals. We used the PSTRE as part of the observational protocol. The PSTRE is an individual assessment; therefore, participants' PSTRE scores from the observed sessions were not used in the analysis because these seven participants worked collaboratively.

The PSTRE does not include any library-based tasks, so research partners at the public library designed a set of website tasks based on the PSTRE framework (Castek, Gibbon, Jacobs, Frank, Honisett, \& Anderson, 2018b). These tasks approximated what the librarians knew to be common activities of library users. Although the tasks were not activities selected by the participants, the problem solving approaches and strategies observed during the completion of those tasks may be transferable to other digital problem solving settings. Castek and Jacobs conducted observations and semi-structured interviews which were audio-recorded. A screen capture program recorded online activities and two researchers took field notes. The screen capture data were archived and later viewed, coded, and analyzed. Detailed transcriptions of key moments captured online and offline activities happening at the same time.

\section{Data Analysis}

Analysis was informed by theories of power. Power can be seen as a product exchangeable for something else, or power can be seen as a process (Bloome et al., 2005). Power also can be understood as caring relations (Bloome, et al., 2005). Power as caring is non-coercive and brings people together for mutual benefit. It involves "action, effort, achievement, accountability, respect, self-determination for self, community, and others" (Bloome et al., p. 165). Understanding power as a set of relations can reveal how individuals work together to produce knowledge and construct a solution to a problem.

Language analysis is one way to identify power relations in action (Bloome, et al., 2005). Language reveals how individuals are positioned within a digital problem solving experience as 
well as the context of the problem being solved. Analysis can also show the roles taken up by the different speakers. As Bloome et al. show, examining talk makes it possible to see power relationships in a given moment and how individuals are able to participate in an event.

Initial analysis included a coding scheme derived from the PSTRE framework. Inductive codes were developed by the whole research team by discussing an excerpt of interest and jointly determining what descriptive word or phrase captured the phenomena. Once we were confident that each coder understood each code and was able to apply it consistently, the team worked in pairs to code different video data. Coded data were shared and discussed. As the team worked through the data, we found that there were moments we repeatedly returned to. The transcripts of those key moments of interest were read through repeatedly, coded and recoded, and discussed in depth by the team. These findings are reported in Castek et al. (2018c).

Discourse analysis, as described by Bloome et al. (2005) was conducted to consider the implications of collaborative digital problem solving. Each excerpt was analyzed line by line for insights into "Who is doing what, to whom, where, and how through the use of language" (Bloome et al., 2005, p. 49). Specifically, the use of pronouns (you/I/we), interrogative versus declarative sentences, interjections, and interactional patterns were considered. Additionally, field notes were used to identify how individuals were physically positioned in relation to the computer monitor, who controlled the mouse, and who read what appeared on the monitor. After the discourse analysis was completed, we used questions derived from Bloome et al. (2005) to interrogate the analysis, which lead to the creation of nine questions or dimensions (Table 2). The dimensions were organized into the thematic categories of power, relationships, and participation.

\section{Findings}


Table 2 includes a synopsis of key excerpts in relation to the thematic categories. Each thematic category includes three dimensions of questions that reveal patterns of power, relationships and participation. The narrative contains analyses of excerpts to illustrate the thematic categories.

*******************insert Table 2 about here $* * * * * * * * * * * * * * * * * * * *$

\section{Dimensions of Power}

Carla and Francis were tasked with figuring out how to use the library's online service of asking a librarian for reading recommendations. At Carla's suggestion, Francis sat directly in front of the computer, and controlled the computer mouse. Carla sat at her side and slightly askew to the computer but within easy viewing.

\section{Line Talk}

$1 \quad$ Francis: Oh, oh, so what are we looking for?

What was it?

2

3

4
Carla: A librarian who can give you reading

Francis: Crime scenes. Ok. So. About, Explore. Oh, that's ebooks huh showing up here.

Carla: What's this one, all these little pictures. What do you think?

\section{Physical Actions}

Physical Actions

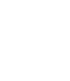


Francis: Banned book week. I like banned book week. (laughs)

6

7

9

11

12
Francis: OK. let's go to my librarian. I was thinking, yeah

Carla: Who would you ask for true crime?

Francis

Francis: I would ask Bob.
10 Carla: Um hum.

1 Francis: Ask Bob.

2 Carla: We would ask Bob
Looking at other pictures on the page.

Identifying the hotlink

Scanning the page with the list of

librarians and their interest areas

Subvocalizing as she reads the webpage.

Identifies the librarian

specializing in True Crime

In line 1, Francis turns to Carla for a reminder of the task. In line 3, Francis takes action on her own by turning to a strategy she had previously learned from Carla (examining menu items). Carla redirects Francis by pointing out another more efficient option using a question (line 4). She does not, however, explain hotlinks to Francis. Once Francis's attention is drawn to the hotlinks, Francis is momentarily distracted (line 5). Once Francis is on the correct webpage, Carla reminds Francis of the task by using a question (line 7). Once Francis finds the information, Carla confirms her choice. 
What roles are taken up? Carla explicitly takes on the role of coach or teacher. She steps in when needed to keep Francis focused on the task. Carla also uses questions to guide Francis (lines 4 and 7). Francis takes on the role of student by seeking Carla's approval (lines 912). This type of exchange may be representative of learning where one person in the dyad holds more knowledge about the task and tools at hand than the other. Although Carla is directive, she uses power as caring to instruct Francis rather than coerce her into a set of behaviors. Francis had the opportunity to learn what was on the library's web page and how to navigate it, and Carla had the opportunity to further her involvement as a Friend of the Library.

\section{Dimensions of Relationships}

Sonja and Ellen used the library website to access MedlinePlus (a free consumer oriented medical website administered by the National Library of Medicine) to find the symptoms of the Zika virus. The library also provides access to Medline, a professional medical database. Users must be able to ascertain the difference between the two types of databases. When they first met, Sonja and Ellen agreed that Sonja should take control of the mouse and keyboard. Ellen said Sonja was probably the faster of the two on the computer. Ellen sat next to Sonja and could see the screen.

\section{Line Talk}

1

Ellen: And the last one is go to Medline Plus database and find the symptoms of the Zika virus.

2

Sonja: Here we go. Medline Plus. Um, (subvocalizing)

\section{Actions}

Typing into library's search bar 
3 Sonja: This is the list of databases. This

Looking at the list of databases.

brings back college memories.

4

Ellen: Yeah. It should

5

Sonja: Medline Plus. Ok. Medline

Scanning the page.

6

Ellen: Plus

7

Sonja: Yeah, I (subvocalizing) a million

Clicking on the link

different things, there was like a million

things for us to, in college, and

(subvocalizing)

8

Sonja: Here. Zika

Scanning the page

9

Ellen: They have a search

Pointing to the search bar.

10

Sonja: Oh perfect. Ok.

Typing

11 Ellen: We want symptoms

12

Sonja:

Typing

13 Ellen: Ok, we looked it up. Do we have to

Looking at results of search. read it?

14 Sonja: Complications (subvocalizing). There Skimming results page. we go. 
How is a relationship expressed? Ellen and Sonja were different in age and education levels, and as a Friend of the Library, Ellen was assumed to have more experience navigating the library's website than Sonja. Like Carla and Francis, the more experienced person took on the role of the viewer. However, the interactional patterns were different. Ellen interjects in three places (lines 6, 9, and 11), but these interjections are short and informational. Unlike Carla, she does not use instructional questioning. In turn, Sonja does not seek Ellen's approval. In line 6, Ellen ensures Sonja clicks on the correct database, and Sonja confirms with a simple "Yeah" (line 7), and in lines 9 and 10, the same pattern of exchange is repeated. In line 14, Sonja states that they found the information but does not seek agreement from Ellen.

The exchange between Sonja and Ellen is representative of power as caring. Information is exchanged throughout the problem solving process. Although Ellen had more experience with the library system, Sonja's youth and recent experience at college appears to have made their relationship collegial rather than that of teacher and student.

Sonja's and Ellen's relationship may have been colored by their educational and work experiences. When talking about their experiences in higher education, Ellen acknowledged Sonja's knowledge of databases (line 4) which Sonja reinforced (line 7). During her years working at an institute of higher education, Ellen may have developed skills and approaches for working with those much younger than her. Rather than being didactic, Ellen was able to allow her younger colleague to lead and to provide support only when needed. Her university experience may also have provided her with the skills to be respectful to Sonja who presented as non-binary. Sonja's college experience may also have been an important point for relationship building. Sonja referred to their college experience several times in conversation with Ellen, which may have been an effort to establish commonalities or equal footing. Both individuals 
said they learned from the experience. Sonja learned more about the library's website, what it offers, and how it differs from what she remembered from college. Ellen told us she learned about Medline Plus as a resource.

\section{Dimensions of Participation}

Sam, Henry, and Andrew were asked to "Find a volunteer opportunity at the library for someone who likes to play chess and wants to work with the public. Find the minimum age for that volunteer to be eligible?" Henry was in control of the mouse and keyboard. The data do not show why Henry took control of the computer. The other two men sat on either side of him. At this point, the three had read the task. Henry looked for the information using the search bar on the library's web page. The talk shown here demonstrates a moment when the three men compare the information they found to the task criteria to determine whether they had achieved the purpose of the task.

\section{Line Talk}

1

2 Henry: Here we go. Chess. Times. Locations.

3 Andrew: Where's the age? They have to have the minimal age.

4 Sam: Uh, it would be adults families, kids, teens, reservations

\section{Actions}

Typing the words volunteer chess

into library webpage search bar 
$5 \quad$ Henry: How the heck do I

6 Sam: That's backwards, so scroll it down

$7 \quad$ Henry: Ah

8

9 Sam: 5:30 at the Holgate library

10 Henry: But we still need to figure out

Sam: That's chess club

Researcher: So that's chess club

11 Henry: But we still need to figure out how to

volunteer to

12 Andrew: Right

Henry: Ah

13 Henry: Who likes to play chess, who likes to
Trying to scroll using the

trackpad

Scrolling

Reading from the webpage

\section{Reading task criteria}

Henry begins the task by silently working on the computer while the others watch. When it becomes apparent that Henry's strategy might not be working, Andrew reminds the group of their task (line 3). Sam helps Henry troubleshoot his issue with scrolling (line 6). In Line 10, all three participants realize that the information retrieved is not helpful just as the researcher 
attempts to step in and redirect their efforts. Andrew confirms with a one word response (line 12). This quick and simultaneous interaction causes Henry to revisit the task (line 13).

How does knowledge sharing occur? This interaction differs significantly from that of Carla and Francis. There was no instructional questioning and this may be because none of the three men have more knowledge than the other or it may be indicative of the participants' preexisting relationship. Although they initially appear to accept Henry taking control of the task, they jointly monitor the task (lines 3 and 10) and speak up as needed. In this way, they are similar to Ellen who contributes to prevent an error being made. As a result of the seemingly equal level of power, all three men have the opportunity to gain a deeper understanding of how to navigate the library website and to think flexibly.

\section{Discussion, Implications, and Limitations}

The findings provide insights that hold promise for creating positive collaborative digital problem solving learning experiences. Having a flexible set of skills, strategies, and mindsets allows individuals to solve problems as they encounter them, thus setting them up for success as they learn across the different contexts and throughout their lives. When learning relationships are built on a model of caring, collaboration becomes a way to learn how to participate in digital problem solving by learning strategies, skills, and approaches that may be new.

Neither Sam, Henry, nor Andrew had more knowledge than the other and each individual contributed to solving the problem once it was clear Henry could not solve it on his own. Carla's and Francis's collaboration could be characterized like that of teacher and student, which was most likely due to Carla's higher level of experience and involvement in the "Friends of the Library" program. Ellen's and Sonja's collaboration was collegial and perhaps predicated on similar educational backgrounds. What is important to pull from these insights is that 
collaboration can look different depending on the individuals involved and the relationships in play.

As seen with Sam, Henry, and Andrew, collaboration may result in problem solvers slowing down and engaging in exploration and discovery within a novel online environment. Collaboration with a supportive partner such as Carla may help less experienced partners such as Francis persist in problem solving when faced with the unknown. In cases such as Ellen and Sonja, collaboration might not be necessary to solve the problem, but allows for an exchange of information, which may have contributed to the pairs' ability to quickly complete the task.

Participants shared and compared information, identified inconsistencies in their understanding of the task, negotiated meaning, examined the task, and applied the constructed meaning before moving forward with the task. They were able to build trust and negotiate meaning through effective social interaction. Participants were systematic in their approach and came to an agreement as they worked to solve the task at hand. All of these problem solving strategies are useful for non-digital problem solving, but become more salient for less digitally experienced individuals working in a digital environment. By learning in a relationship built through power as caring, the digital world may become less intimidating and more accessible.

\section{Implications for Practice}

Practitioners can use the ideas presented in this analysis to better understand how adolescents, adults, and underserved people in particular, might engage in digital problem solving when allowed to do so in collaborative settings. Practitioners may find it worth the time to discover learners' previous experience with learning, digital technology, and with each other. However, it may not be necessary to partner learners by experience level. More experienced learners do not necessarily have to be partnered with less experienced learners. As our data 
suggest, the experience level of individuals may be less important than the ability of the individuals to negotiate roles and use skills they do have.

By drawing on an understanding of different interactional patterns, practitioners can determine when and if support might be needed during a learning activity. Specific patterns can include (a) when a partner takes on the role of teacher (such as Carla did with Francis) (b) when partners share power and contribute using the unique knowledge they bring to the situation (such as Sonja and Ellen), or (c) share power with each participant equally working to solve a problem such as Henry, Sam, and Andrew.

As the relationship between Carla and Francis shows, the pattern of teacher/student can be one of nurturing and caring. When designing collaborative digital problem solving opportunities, practitioners need to watch for moments when the more knowledgeable partner takes control of the task rather than acting as a caring guide. Intervention or modeling before beginning a collaborative problem solving session may be needed. In situations where learners have similar educational backgrounds but different life experiences (such as Ellen and Sonja), practitioners need to allow for seemingly off-task conversation that serves to build common ground and respect between the learners. When a group is more homogeneous in knowledge and background, as is the case with Henry, Sam, and Andrew, practitioners need to allow time for the learners to stumble and work through the process of building a solution. Practitioners may see other patterns arising. Constructing tasks where learners can collaborate creates opportunities for learners to become more flexible in how they approach a digital problem.

\section{Limitations}

The data from the background survey did not identify the nuances of participants who attained some post-secondary education. Responses from the seven individuals in the study 
might referring to several different kinds of education background experiences ranging from one course at a vocational school or community college to having attended multiple full-time semesters at a university. The survey also did not capture the timing of when participants were in school. How much post-secondary education, the type of education, and the number of years since being in class would have an impact on their experience with digital resources.

Additionally, we did not describe the prior relationship of Henry, Sam, and Andrew. We intentionally did not ask probing personal questions out of respect for the conditions of their lives and instead allowed those to emerge naturally through our conversations. This lack of data limits the claims we can make about the nature of their collaboration and leaves open the question of how prior relationships figure into collaborative digital problem solving.

\section{Conclusions}

Although collaboration is recognized as an important part of full participation in an online world (Jenkins, 2006), little attention has been given to collaboration as a way to learn digital problem solving. The analysis discussed in this article raises questions about how the life experiences of individuals impacts their access to digital resources and their facility with digital problem solving. The complexity of learners' lives, the interactional patterns that occur while collaborating, and how caring learning experiences can be constructed are all important aspects to consider when designing collaborative experiences for digital problem solving. When faced with the challenges of digital problem solving, individuals may benefit from opportunities to collaborate rather than trying to go it alone.

\section{Acknowledgement}

This project was made possible in part by an Institute of Museum and Library Services National Leadership Grant (LG-06-14-076-14A). 


\section{References}

American Library Association (ALA) Digital Literacy Task Force (2013). ALA Task Force releases digital literacy recommendations. Retrieved from http://www.ala.org/news/pressreleases/2013/06/ala-task-force-releases-digital-literacy-recommendations

Barrie, H., LaRose, T., Detlor, B., Julien, H., \& Serenko, A. (2020). “Because I'm old”: The role of ageism in older adults' experiences of digital literacy training in public libraries. Journal of Technology in Human Services. DOI: 10.1080/15228835.2021.1962477

Barton, D. (2001). Directions for literacy research: Analysing language and social practices in a textually mediated world. Language and Education, 15(2), 92 -104.

Barton, D., \& Hamilton, M. (1998). Local literacies: Reading and writing in one community. London: Routledge.

Barton, D., Hamilton, M., \& Ivanič, R. (2005). Situated literacies: Reading and writing in context. London: Routledge.

Bloome, D., Carter, S.P., Christian, B.M., Otto, S. and Shuart-Faris, N. (2005). Discourse analysis and the study of classroom language and literacy events: A microethnographic perspective. Mahwah, NJ: Lawrence Erlbaum.

Castek, J., Jacobs, G., Gibbon, C., Frank, T., Honisett, A., Anderson, J., (2018a). Defining Digital Problem Solving. Advancing Digital Equity in Public Libraries: Assessing Library Patrons’ Problem Solving in Technology Rich Environments. PDX Scholar. https://pdxscholar.library.pdx.edu/digital_equity_toolkit/3/

Castek, J., Gibbon, C., Jacobs, G., Frank, T., Honisett, A., Anderson, J., (2018b). Blueprint for Designing Digital Problem Solving Tasks. Advancing Digital Equity in Public Libraries: 
Assessing Library Patrons' Problem Solving in Technology Rich Environments. PDX

Scholar. https://pdxscholar.library.pdx.edu/digital_equity_toolkit/1/

Castek, J., Jacobs, G., Gibbon, C., Frank, T., Honisett, A., Anderson, J., (2018c). Executive Summary. Advancing Digital Equity in Public Libraries: Assessing Library Patrons' Problem Solving in Technology Rich Environments. PDX Scholar. https://pdxscholar.library.pdx.edu/digital_equity_findings/1/

Courtois, C., and Verdegem, P. (2016). With a little help from my friends: An analysis of the role of social support in digital inequalities. New Media and Society, 18(8), 1508-1527.

Fairclough, N. (2010). (Ed.). Discourse and Contemporary Social Change. Bern.

Gee, J. P. (2000). The new literacy studies and the "social turn". In D. Barton, M. Hamilton \& R. Ivanic (Eds.), Situated Literacies: Reading and Writing in Context (pp. 180-196). London: Routledge.

Heath, S. B. (1982b). What no bedtime story means: narrative skills at home and school. Language in Society, 11(1), 49-76.

Helsper, E., and van Deursen, A. J. A. M. (2017). Do the rich get digitally richer? Quantity and quality of support for digital engagement. Information, Communication and Society, 20(5), 700-714. Retrieved from https://doi.org/10.1080/1369118X.2016.1203454

Jacobs, G. \& Castek, J. (2018). Digital problem solving: The literacies of navigating life in the digital age. Journal of Adolescent and Adult Literacy, 61(6), 681-685.

Jacobs, G., Castek, J., Pizzolato, D., Pendell, K., Withers, E., \& Reder, S. (2015). Executive Summary: Tutor-facilitated digital literacy acquisition in hard-to-serve populations, a research project. PDX Scholar. https://pdxscholar.library.pdx.edu/digital_literacy_acquisition_findings/9/ 
Jenkins, H. (2006) Confronting the Challenges of Participatory Culture: Media Education for the 21st Century. John D. and Catherine T. MacArthur Foundation, Chicago

Kiili, C., Leu, D., Utrainen, J., Coiro, J., Kanniainen, L.,Tolvanen, A., Lohvansuu, K., \& Leppanen, P. (2018). Reading to learn from online information: Modeling the factor structure. Journal of Literacy Research. 50, 304-334. Retrieved from https://doi.org/10.1177/1086296X18784640

Lin, C., Hou, H., and Tsai, C. (2016). Analyzing the social knowledge construction and online searching behavior of high school learners during a collaborative problem solving learning activity: A multi-dimensional behavioral pattern analysis. The Asia-Pacific Education Researcher, 25(5-6), 893-906. doi:10.1007/s40299-016-0317-y

Mehan, H. (1979). Learning lessons. Cambridge, MA: Harvard University Press. https://doi.org/10.4159/harvard.9780674420106

OECD. (2009). PIAAC problem solving in technology-rich environments: A conceptual framework (No. 36). Retrieved from http://www.oecd-ilibrary.org/education/piaacproblem-solving-in-technology-rich-environments-a-conceptualframework_220262483674

Rosen D. J., and Vanek, J. B. (2017). Technology for innovation and change in adult basic skills education. New Directions for Adult and Continuing Education (155), 51-60.

Sharp, L. A. (2018) Collaborative digital literacy practices among adult learners: Levels of confidence and perceptions of importance. International Journal of Instruction, 11(1), $153-166$.

Sieck, C.J., Sheon, A., Ancker, J.S.,Castek, J., Callahan, B., and Siefer, A. (2021). Digital inclusion as a social determinant of health. npj Digit. Med. 4, 52. 
https://doi.org/10.1038/s41746-021-00413-8

Street, B. (1984). Literacy in Theory and Practice. Cambridge: Cambridge University Press.

van Laar E, van Deursen A, van Dijk J, and de Haan, J. (2017). The relation between 21stcentury skills and digital skills: A systematic literature review. Computers in Human Behavior, 72, 577-588.

van Laar, E., van Deursen, A. J. A. M., van Dijk, J. A. G. M., and de Haan, J. (2018). 21stcentury digital skills instrument aimed at working professionals: Conceptual development and empirical validation. Telematics and Informatics, 35(8), 2184-2200. Retrieved from https://doi.org/10.1016/j.tele.2018.08.006 
Table 1.

Participant Demographics

\begin{tabular}{|c|c|c|c|c|c|c|c|c|}
\hline Group & Name & $\begin{array}{l}\text { Age } \\
\text { range }\end{array}$ & Gender & $\begin{array}{l}\text { Highest level } \\
\text { of education }\end{array}$ & $\begin{array}{l}\text { Home } \\
\text { Internet }\end{array}$ & $\begin{array}{l}\text { Home } \\
\text { computer }\end{array}$ & $\begin{array}{l}\text { Primary } \\
\text { Internet } \\
\text { Location }\end{array}$ & $\begin{array}{l}\text { Mobile as } \\
\text { primary } \\
\text { access }\end{array}$ \\
\hline $\mathrm{A}$ & Andrew & $35-44$ & Male & $\begin{array}{l}\text { Some Post- } \\
\text { secondary }\end{array}$ & Yes & Yes & Library & Yes \\
\hline A & Henry & $35-44$ & Male & $\begin{array}{l}\text { Some Post- } \\
\text { secondary }\end{array}$ & Yes & Yes & Phone & Yes \\
\hline A & Sam & $35-44$ & Male & $\begin{array}{l}\text { Some Post- } \\
\text { secondary }\end{array}$ & No & No & Library & Yes \\
\hline B & Carla & $25-34$ & Female & $\begin{array}{l}\text { Beyond a } \\
\text { college degree }\end{array}$ & Yes & Yes & At work & No \\
\hline B & Francis & $45-54$ & Female & Primary & No & No & Library & Yes \\
\hline D & Ellen & over 65 & Female & $\begin{array}{l}\text { Beyond a } \\
\text { college degree }\end{array}$ & Yes & Yes & Home & No \\
\hline D & Sonja & $25-34$ & Non-binary & 4 year degree & Yes & Yes & Home & Yes \\
\hline
\end{tabular}

Notes. All names are pseudonyms. 


\title{
Table 2.
}

\section{Themes, Dimensions of Those Themes, and Examples from Dialogic Interactions}

\author{
Theme 1: Power operationalized as differing expertise with digital skills
}

\begin{abstract}
Dimension 1: What roles Roles represent either the persona or the tasks each individual takes on.
are taken up?

Carla, who has advanced education and more experience with digital problem solving, takes on the role of teacher. Francis takes on the role of learner. Carla's interactions with Francis follow the Initiation / Response / Evaluation discourse pattern frequently used by teachers (Mehan, 1979). She begins with a direction followed by a question. Francis's response is evaluated either by Carla or by the computer which shows the correct webpage.
\end{abstract}

Ellen and Sonja each take on different but equal roles. Sonja takes on the role of working the computer, and Ellen takes on the role of monitoring the progress and double checking work.

Sam, Henry, and Andrew also take on slightly different roles. Henry controls the computer, Sam provides oversight and guidance on technical issues, and Andrew holds the overall goal of the problem in mind and steps in to remind the group of the task when needed.

Dimension 2: Who gets to Power is demonstrated by who gets to speak and who gets heard.

speak/Who gets heard?

Ellen and Sonja demonstrate fairly equitable power relationships. Ellen and Sonja are different in age and education levels. Sonja has more experience using computers and Ellen has more experience navigating library services. Ellen interjects in three places to remind Sonja of a nuance of the task or to point out a 
feature of the website Sonja missed. Sonja handles the keyboard and mouse and skims the web pages while reading aloud. Ellen responds to Sonja's comments with statements that support or redirect Sonja, but she does not tend to extend or build on what Sonja says. Sonja listens to Ellen's comments and takes action, and Sonja's actions lead Ellen to speak.

Carla tends to control the flow of conversation by directing Francis with questions, which Francis responds to. Carla also chooses which of Francis's utterances to respond to and which to ignore.

Sam and Henry initially ignore or miss Andrew's first utterance that attempts to direct them to the main purpose of the task, but after coming to a similar conclusion on their own, Andrew repeats his stance.

Dimension 3: What skills, Levels of expertise represent the skills, knowledge, and experience brought to a knowledge, and experience problem.

is privileged?

Henry, Sam, and Andrew all have similar levels of education, life experiences, and experience with digital problem solving. No one has more expertise than the other and they live within a transitional community that depends on the sharing of knowledge of resources to survive (where to find meals, housing, health care, etc.). Henry and Sam simultaneously realize that what they found does not meet the requirements of the task. Andrew confirms Henry and Sam's realization with a one word response, "Right". This quick interaction causes Henry to revisit the problem. 
Carla has more experience and knowledge of digital tools and the library website and thus she maintains control of the digital problem solving task throughout her time with Francis.

Ellen and Sonja each bring a unique set of digital problem solving experiences to the task. Sonja is a fairly recent college graduate who used databases within her educational experience and also uses computers to manage household expenses and tasks. Ellen worked in an academic environment and has a high level of knowledge of the library website.

Theme 2: Relationships operationalized as how ideas among peers require constant shifts in power relations

Dimension 1: How is leadership negotiated?

Dimension 2: How is a relationship expressed?

Carla begins the exchange by using the second person pronoun "you" to explain the task. At the end of the exchange, Carla uses the first person "we" when confirming the answer thus positioning her and Francis as a team rather than teacher/student.

When discussing the task, Sonja uses the first person "we" to indicate they are starting a task. Ellen interjects with short pieces of information when she sees Sonja potentially making an error. However, unlike Carla, she does not use instructional questioning. In turn, Sonja does not seek Ellen's approval of her actions. She ends the task with a statement of fact.

Dimension 3: How is a peer relationship expressed?
Throughout their conversations, Sam, Henry, and Andrew all use the first person "we" when discussing the task. Andrew interjects to remind the group of the key point of their task, and Sam helps Henry troubleshoot an issue with scrolling. Both of these interjections are done as points of information rather than as a way to teach. When Sam gives Henry information about the scrolling Henry responds with an "Ah" to indicate a moment of understanding. 
Theme 3: Participation operationalized as responses to working together in the context in which the collaboration occurred

Dimension 1: How does Knowledge sharing typically occurred around building an understanding of the knowledge sharing occur? problem being solved.

Carla shares her knowledge of the library website and her understanding of the task by leading Francis through the process using questions. At one point, however, Francis is able to use her understanding of the task to identify an aspect of the problem that Carla had missed.

Similarly, Andrew shared his insight into the problem when it became apparent that the group was misunderstanding what the problem was asking. His first attempt to voice his understanding was not taken up by the others, but once the others came to the same understanding, Andrew re-voiced his perspective.

Sonja contributed to the problem solving through her facility with using the hardware as well as her experience with working with databases. Ellen contributed by using her skill in focusing on the problem to ensure they met the criteria of the task.

Dimension 2: How is turnCarla and Francis have clear turns at speaking; however, Carla tends to lead the taking negotiated? conversation with directive questions. Francis's utterances are typically either in response to Carla's question or a tangential comment triggered by something she sees on the website. Carla's responses to Francis typically include a recognition of Francis's utterance and then a question that redirects Francis's attention. Thus, Carla tends to control how Francis participates. 
Henry, Sam, and Andrew have fairly unstructured turns wherein each utterance is triggered by the task, what is one the screen, or a problem to be solved. At one point, the three each speak nearly simultaneously as they realize the direction they are going is unproductive. This suggests equitable positions toward solving the task.

Sonja speaks when working through the problem, and Ellen waits until Sonja is done explaining where she is in the problem solving process.

Dimension 3: How is the work shared?
Carla and Francis have the clearest division of labor. Because Carla takes on the role of teacher or tutor. Carla ratifies Francis's actions with utterances that indicate approval.

Although Henry is in control of the mouse, Sam directs him when needed and the two talk through the problem at times. Andrew appears to act as a check on the progress of the group and typically speaks only when he identifies an issue in the direction the group is going.

Sonja controls the mouse, and Ellen monitors Sonja's actions and speaks when it seems apparent that Sonja needs some guidance. Sonja's utterances consist of a running $\log$ of where they are in the problem solving process. 